\title{
The Impact of COVID-19 on Sexual Behavior and Psychosocial Functioning in a Clinical Sample of Men who have Sex with Men Using HIV Pre-exposure Prophylaxis
}

\author{
Brooke G. Rogers ${ }^{1,2,3}$ D . Jun Tao ${ }^{1,2} \cdot$ Spencer C. Darveau² $\cdot$ Michaela Maynard $^{1} \cdot$ Alexi Almonte $^{1} \cdot$ Siena Napoleon $^{1}$. \\ Matthew Murphy ${ }^{2,4}$. Philip A. Chan ${ }^{1,2,4}$
}

Accepted: 4 June 2021 / Published online: 10 June 2021

(c) The Author(s), under exclusive licence to Springer Science+Business Media, LLC, part of Springer Nature 2021

\begin{abstract}
The purpose of this study was to evaluate the impact of the Coronavirus Disease 2019 (COVID-19) pandemic on sexual behavior, mental health, and substance use among men who have sex with men (MSM) engaged in pre-exposure prophylaxis (PrEP) care. Generalized linear mixed models and logistic mixed-effect models examined change over time for number of sexual partners, mood, and alcohol consumption. From February 29, 2020 to July 31, 2020, 177 MSM actively engaged in PrEP care were evaluated. The median age was 37 [interquartile range (IQR 30, 51]. Patients in the sample were largely representative of the clinic population and identified as White (73.0\%), Black/African American (9.2\%), and other race (17.2\%), and 11.8\% identified as Hispanic/Latino ethnicity. Men reported an average of 2.60 fewer sexual partners (95\% $\mathrm{CI}-4.04,-1.40)$ during the pandemic compared to pre-COVID-19. Rates of depressive symptoms and alcohol use remained stable and few patients reported substance use. The reduced number of sexual partners may be explained by patients' efforts to reduce risk of exposure to COVID-19 and low rates of psychosocial symptoms may be indicative of only the highest functioning patients continuing to engage in care. Reductions in sexual partners may offset reduced engagement in care and help mitigate risk of HIV and other sexually transmitted infections (STIs).
\end{abstract}

Keywords COVID-19 $\cdot$ Men who have sex with men (MSM) $\cdot$ Sexual behavior $\cdot$ Pre-exposure prophylaxis $\cdot$ Mood · Alcohol

\section{Resumen}

El propósito de este estudio fue evaluar el impacto que tuvo la pandemia causada por la enfermedad del coronavirus 2019 (COVID-19) en el comportamiento sexual, la salud mental y el uso de sustancias en hombres que tienen sexo con hombres (HSH) que reciben profilaxis previa a la exposición (PrEP). Los modelos lineales mixtos generalizados y los modelos logísticos de efectos mixtos examinaron el cambio a través del tiempo en el número de parejas sexuales, el estado de ánimo y el consumo de alcohol. Desde el 29 de febrero de 2020 hasta el 31 de julio de 2020, se evaluaron 177 HSH que recibían los servicios de la PrEP. La mediana de edad fue de 37 (rango intercuartílico (IQR: 30, 51). Los pacientes de la muestra eran en

Philip A. Chan

philip_chan@brown.edu

1 Division of Infectious Diseases, Department of Medicine, The Miriam Hospital, Providence, RI, USA

2 Department of Medicine, Warren Alpert Medical School of Brown University, 14 Third Street, Providence, RI 02906, USA

3 Department of Psychiatry and Human Behavior, Warren Alpert Medical School of Brown University, Providence, RI, USA

4 Open Door Health, Providence, RI, USA 
gran parte representativos de la población de la clínica y se identificaban como Blancos (73.0\%), Negros/Afroamericanos (9.2\%) y de Otra raza (17.2\%) y el $11.8 \%$ se identificó de origen Hispano/Latino. Los hombres reportaron un promedio de 2.60 parejas sexuales menos (IC del 95\%: -4.04, -1.40) durante la pandemia en comparación con antes de COVID-19. Las tasas de síntomas depresivos y el uso de alcohol se mantuvieron estables y pocos pacientes reportaron uso de sustancias. El número reducido de parejas sexuales puede explicarse por los esfuerzos de los pacientes para reducir su riesgo de exposición al COVID-19 y las bajas tasas de síntomas psicosociales pueden ser indicativos de que solo los pacientes con mayor funcionamiento continúan participando. La reducción en el número de parejas sexuales puede contrarrestar la baja participación en la atención medica de la PrEP y ayudar a mitigar el riesgo de contraer el VIH y otras infecciones de transmisión sexual (ITS).

\section{Introduction}

The Coronavirus Disease 2019 (COVID-19) pandemic caused by severe acute respiratory syndrome coronavirus 2 (SARS-CoV-2) has fundamentally changed healthcare and aspects of life since January 2020. COVID-19 has resulted in significant morbidity and mortality worldwide, with the United States leading in number of cases and mortality rates. There have been over 60 million cases and over 1.4 million deaths worldwide, with 12.65 million cases and 260,000 deaths in the United States alone [1]. Apart from the physical toll that COVID-19 has had on the health of the population, the pandemic has led to unprecedented behavioral changes, mental health consequences, and healthcare delivery transformations [2-4]. These challenges have not been proportional for all populations in the United States, and the pandemic has exposed significant flaws in healthcare services delivery and access, which has compounded the crisis [5].

The COVID-19 pandemic has affected access to preventive healthcare [6]. More specifically, COVID-19 has compounded pre-existing inequities in access to preventive healthcare in vulnerable populations, including those at risk for and living with HIV [7-9]. Reduced access to HIV preventative care can potentially lead to higher rates of HIV acquisition over time. For example, individuals may not have access to medications, such as pre-exposure prophylaxis (PrEP) for HIV prevention, or sexually transmitted infection (STI) testing, which both place these individuals at a higher risk of acquiring HIV [10]. Those individuals living with HIV may also have reduced access to healthcare, including HIV medications, which could lead to drug resistance or an increased viral load of HIV, resulting in increased risk of transmission [11].

One understudied area is how COVID-19 has affected sexual behaviors over time and how that might in turn affect HIV risk. More specifically, it has not been well-described how changes in social and sexual behaviors due to COVID19 may impact HIV risk in gay, bisexual and other men who have sex with men (MSM) who have the greatest burden of HIV [12]. Additionally, psychosocial syndemic factors have been shown to be associated with sexual risk [13-16], poor antiretroviral medication adherence and viral suppression
[17-19], and PrEP adherence [20] in MSM increasing risk for both HIV transmission and acquisition.

The goal of the current study was to examine changes in sexual behavior and psychosocial functioning operationalized as depressive symptoms, alcohol use, and substance use among MSM engaged in PrEP care prior to and during the COVID-19 pandemic.

\section{Methods}

\section{Participants and Procedures}

We reviewed medical records for all cisgender male PrEP patients who self-identified as men who have sex with men (MSM) and were engaged in care at the major PrEP program in Rhode Island. We included PrEP patients who had been engaged in care and attended PrEP visits during the time phases analyzed for this study. We included patients who had two or more PrEP clinical visits during the study period. The study sample represents approximately one third of active PrEP clinic patients. Demographic and background information was obtained from review of clinical records. Procedures for the review of de-identified clinic data were approved by The Miriam Hospital Institutional Review Board.

\section{Defining COVID-19 Pandemic Phases}

We divided the study period into three phases according to the COVID-19 pandemic status in Rhode Island: 1) pre-COVID-19 (before February 29th, 2020), 2) emerging (March 1st, 2020-April 11th, 2020, 3) and plateau phase (April 12th, 2020-July 31st, 2020). The first confirmed COVID-19 case was reported on February 29th, 2020 in Rhode Island; we defined the pre-COVID-19 phase as starting approximately six months prior to the first case and ending on February 29th, 2020. We defined from March 1st to April 11th, 2020 as the emerging phase, during which we observed exponential growth in the number of confirmed COVID-19 cases, and during which many individuals in Rhode Island experienced a change in work environment from on-site to remote (if and when possible) and/or 
shutdowns at their place of employment. April 12th until the final date in our dataset (July 28) was considered the "plateau phase" during which individuals had adjusted to COVID-19 restrictions and limitations. It was also during this period that there was a national and local reopening of retail and other services that had previously been closed.

\section{Clinic Procedures}

Prior to the COVID-19 pandemic, the PrEP clinic offered inperson appointments only. During the pandemic, the clinic shifted to telehealth visits for PrEP appointments with inperson appointments being limited and scheduled on an as needed basis based on clinical judgement. Patients scheduled to be seen for an in-person appointment were called by clinical staff and were screened for COVID-19 via a phone-based symptom screening protocol prior to their appointment. The rapid shift to telehealth helped maintain PrEP clinical care. As part of routine PrEP care, providers asked patients about the items reported within this manuscript including symptoms, adverse effects, psychosocial functioning, substance use, and medication adherence.

\section{Measures}

Psychosocial functioning was operationalized as depressive symptoms, alcohol use, and substance use. Depressive symptoms were screened using the patient health questionnaire-2 (PHQ-2), which is a two-item depression screener that assesses the frequency of low mood and anhedonia over the past two weeks. Each item ranges from 0 -not at all, to 3 -nearly every day. Total scores range from 0 to 6 , with scores greater than or equal to 3 indicating a positive screen for depression [21]. Problematic alcohol use was assessed by the alcohol use disorders identification test (AUDIT-C), which is a 3-item alcohol screen that helps identify individuals with problematic alcohol use and specifically assesses frequency and quantity of drinking. Each item is ranked on a scale of $0-4$ points, with a higher number of points indicating more problematic drinking. Total scores range from 0 to 12 and a score above 4 or more in men is considered as a positive screen for a potential alcohol use disorder [22]. Substance use was assessed by the following question for each substance "Do you use substances? Yes/No." The following substances were collapsed into the category "party drugs": crystal methamphetamine, cocaine, ecstasy/MDMA/Molly, and gamma hydroxybutyrate (GHB). Heroin and prescription opioid medications were collapsed into the category opioids. We also assessed medication adherence to PrEP by two questions: How many doses of PrEP did you miss in the past week? How many doses of PrEP did you miss in the past 30 days? The higher the number of missed doses the lower the adherence.

\section{Statistical Analyses}

Descriptive statistics were used to characterize the sample. Mixed effects modeling was used to examine between and within persons' change over time across multiple outcomes (e.g. PrEP adherence, sex behaviors, alcohol and substance use, and depressive symptoms). Generalized linear mixed models were used for continuous outcomes and logistic mixed-effect models were used for binary outcomes. Directed acyclic graphs and a priori knowledge were used to determine covariates. An alpha of 0.05 was used as the cutoff for significance. All analyses were conducted in Stata 15.0 (StataCorp LP, College Station, Texas).

\section{Results}

\section{Sample Characteristics}

Of 177 patients included in the sample, the median age was 37 (interquartile range (IQR 30, 51). The median number of PrEP visits was 5 (IQR 3, 8). The patients included in the study sample were largely representative of the clinic population and identified as White $(73.0 \%)$, Black/African American (9.2\%), and Other race (17.2\%), and $11.8 \%$ of the sample identified as Hispanic/Latino. Most patients had a college degree or above (73.5\%). The median income was $\$ 50,000$ (IQR 34,000-\$80,000). With regards to sexual behavior, at their initial clinic visits, $78.5 \%$ reported engaging in condomless anal sex, $29.9 \%$ reported having 5 partners or more in the past 30 days, and $15.9 \%$ reported sex with known HIV positive partners. With regards to psychosocial health, $32.8 \%$ endorsed a history of a mental health condition. In the time period observed for the current study only $3.1 \%$ screened positive on the PHQ-2. Approximately $64.8 \%$ of MSM endorsed drinking behavior that could be problematic based on their AUDIT-C score. Approximately $46.6 \%$ reported drug use in their lifetime, but few reported current drug use (7.2\%), with most reporting stimulants or other "party drug" use (e.g. inhalants, GHB). None reported opioid use.

\section{Changes in Sexual Behavior}

In the generalized linear mixed effect models, we explored changes in sex behaviors and PrEP adherence during different phases of COVID-19. On average, PrEP patients reported 2.72 fewer sexual partners $(95 \% \mathrm{CI}-4.04,-1.40$; $p<0.001)$ during the plateau phase compared to the preCOVID-19. Patients also reported 1.66 fewer oral sex partners $(95 \%$ CI $-3.07,-0.25 ; p=0.02)$ during the emerging phase and 2.88 fewer oral sex partners $(95 \%$ CI $-4.01,-1.75 ; p<0.001)$ during the plateau phase. 
Importantly, they also reported 1.65 fewer condomless anal sex partners $(95 \% \mathrm{CI}-2.78,-0.53 ; p=0.004)$ during the plateau phase. The median number of sexual partners during the plateau phase dropped to one, representing a statistically significant reduction in the average number of sex partners [median $=1$, (IQR 1,3), $p<0.001$ ].

\section{Changes in Psychosocial Functioning: Adherence, Mood, and Alcohol Use}

We did not observe any significant difference in PrEP adherence, depression, or alcohol use over time. We conducted a secondary analysis to look more closely at behaviors of those who endorsed heavy drinking and found that there was a significant positive association between heavy alcohol use and sexual partners. Those with a positive AUDIT-C screen reported, on average, a significantly larger number of sexual partners [Beta coefficient $=1.26,95 \%$ CI $(0.20$, 2.32), $p=0.02$ ]. Too few individuals in the sample reported substance use to examine the effects on sexual partners or behavior. For full model results, see Table 1.

\section{Discussion}

This is among the first studies to evaluate sexual behavior and psychosocial functioning among MSM engaged in PrEP care during the COVID-19 pandemic. We observed significant decreases in the number of sexual partners reported by MSM engaged in PrEP care during both the emerging and plateau stages of COVID-19, compared to baseline levels. This was true for oral sex partners, anal sex partners, and condomless sex partners. However, the number of condomless sex partners was not significantly decreased at the plateau stages, indicating that decreases observed in other phases may be better accounted for by overall decreases in sexual partners. We did not observe significant worsening of PrEP adherence, depression, or alcohol use over the time periods observed. The limited number of PrEP patients who reported current drug use prevent us from conducting any meaningful analyses on changes in substance use behavior.

Our findings can be contextualized within several studies conducted using online convenience samples of MSM during the pandemic which have explored self-reported sexual behavior and associations with mental health and substance use. Findings have been mixed. For example, early in the pandemic, several studies showed that MSM reported fewer sexual partners and decreases in sexual HIV transmission behavior [23-25]. A different study based in the U.S. found MSM continued to report high levels of sexual activity, substance use, and binge drinking during the pandemic [26]. In our sample, we observed decreases in the number of sexual partners; however, we did not collect data on frequency of sexual behavior with each partner. Thus, it is possible that individuals in our sample were still engaging in similar levels of sexual behavior, but with fewer partners. If true, this would be consistent with public health recommendations to limit the number of social contacts to reduce the spread of SARS-CoV-2 throughout the population [27].

Our findings for alcohol and depression were counterintuitive. As a group, individuals in our sample did not report depressive symptoms or heavy alcohol use at higher rates during COVID-19 at rates higher than pre-COVID-19. However, we did find that individuals who were heavy alcohol users (based on AUDIT-C scores) reported more sexual partners. This finding is consistent with prior studies demonstrating strong relationships between alcohol consumption,sexual behavior, and potential for HIV transmission [28-30]. A study conducted by Starks and colleagues (2020) during the pandemic observed amplified relationships between substance use and sexual behavior during the pandemic such that individuals who are using substances are also engaging in higher risk sexual behaviors [31]. According to cognitive behavioral treatment models, substance use and sexual behavior can be broadly conceptualized as "avoidance behaviors" used to cope with negative affective states characteristic of emotional disorders [32]. Both substance use and sex provide short-term relief for feelings of loneliness, depression, and anxiety; all of which have been noted to be on the rise during the COVID-19 pandemic $[33,34]$. However, within this sample, we did not observe higher levels of depression or alcohol use over time.

Our study strengths must be interpreted in light of the limitations. Patients self-reported number of sexual partners, which is subject to the typical limitations of retrospective self-report. We recognize that social desirability bias and demand characteristics may have affected accurate reporting of mental health symptoms and substance use behavior in a medical clinic setting. Additionally, in order to make comparisons over time, we restricted analyses to those patients who had completed at least two visits across the three phases of interest. However, that also means that we may have selected for a more highly engaged group of patients. This may be one possible explanation for not observing changes in mood or alcohol is that those that were presenting to care were functioning well and those whose mood or alcohol has worsened may not present to care. This is substantiated by prior research demonstrating the impact of mood and substance use on poor engagement in health care [35] including sexual health and HIV related care [36].

In conclusion, on average, patients in our sample reported fewer sexual partners in the emerging and plateau phases of COVID-19 compared to prior to COVID-19. Of note, in the plateau phase, the median number of sexual partners patients reported was one. Reducing the number of sexual partners likely reduced the number of social contacts individuals 
Table 1 Mixed effect models to assess sexual behavior, PrEP adherence, depressive symptoms, and alcohol use over time

\begin{tabular}{|c|c|c|c|c|c|}
\hline COVID-19 phase & Median (IQR) & $\begin{array}{l}\text { Crude beta coefficient and } 95 \% \\
\text { confidence interval (CI) }\end{array}$ & $P$ value & $\begin{array}{l}\text { Adjusted beta coefficient and } \\
95 \% \text { CI }\end{array}$ & $P$ value \\
\hline \multicolumn{6}{|c|}{ Total number of sex partners } \\
\hline Pre-COVID-19 & $3(2,5)$ & Reference & & & \\
\hline Emerging & $3(1,4)$ & $-0.60(-2.15,0.96)$ & 0.45 & $-0.77(-2.42,0.87)$ & 0.35 \\
\hline Plateau & $1(1,3)$ & $-2.60(-3.87,-1.35)$ & $<0.001$ & $-2.72(-4.04,-1.40)$ & $<0.001 * * *$ \\
\hline \multicolumn{6}{|c|}{ Total number of oral partners } \\
\hline Pre-COVID-19 & $4(2,7)$ & Reference & & & \\
\hline Emerging & $3(2,4)$ & $-1.23(-2.56,0.11)$ & 0.07 & $-1.66(-3.07,-0.25)$ & $0.02 *$ \\
\hline Plateau & $2(1,3)$ & $-2.45(-3.52,-1.36)$ & $<0.001$ & $-2.88(-4.01,-1.75)$ & $<0.001 * * *$ \\
\hline \multicolumn{6}{|c|}{ Total number of condomless anal sex } \\
\hline Pre-COVID-19 & $2(1,4)$ & Reference & & & \\
\hline Emerging & $2(1,3)$ & $0.01(-1.27,3.29)$ & 0.99 & $-0.29(-1.65,1.00)$ & 0.67 \\
\hline Plateau & $1(1,2)$ & $-1.34(-2.41,-0.26)$ & 0.02 & $-1.65(-2.78,-0.53)$ & $0.004 * * *$ \\
\hline \multicolumn{6}{|c|}{ No. of missing doses in the previous week } \\
\hline Pre-COVID-19 & $0(0,0)$ & Reference & & & \\
\hline Emerging & $0(0,0)$ & $0.01(-0.27,0.29)$ & 0.94 & $0.05(-0.24,0.35)$ & 0.81 \\
\hline Plateau & $0(0,0)$ & $-0.11(-0.34,0.11)$ & 0.32 & $-0.09(-0.33,0.14)$ & 0.43 \\
\hline \multicolumn{6}{|c|}{ No. of missing doses in the previous month } \\
\hline Pre-COVID-19 & $0(0,1)$ & Reference & & & \\
\hline Emerging & $0(0,1)$ & $-0.17(-1.27,0.94)$ & 0.77 & $-0.0004(-1.16,1.16)$ & 0.99 \\
\hline Plateau & $0(0,1)$ & $-0.63(-1.52,0.26)$ & 0.17 & $-0.54(-1.46,0.39)$ & 0.26 \\
\hline COVID-19 phase & $\begin{array}{l}\text { Positive screen for } \\
\text { depression }(\mathrm{N})\end{array}$ & $\begin{array}{l}\text { Crude odds ratio (cOR) and 95\% } \\
\text { confidence interval (CI) }\end{array}$ & $P$ value & $\begin{array}{l}\text { Adjusted odds ratio (aOR) } \\
\text { and } 95 \% \text { CI }\end{array}$ & $P$ value \\
\hline \multicolumn{6}{|c|}{ Screened depression (PHQ-2) } \\
\hline Pre-COVID-19a & 7 & Reference & & & \\
\hline Emerging $^{\mathrm{b}}$ & 2 & $0.79(0.15,4.09)$ & 0.78 & $0.52(0.16,4.29)$ & 0.81 \\
\hline Plateau $^{\mathrm{c}}$ & 3 & $0.38(0.09,1.57)$ & 0.18 & $0.38(0.09,1.58)$ & 0.18 \\
\hline \multicolumn{6}{|c|}{ Screened drinking problem (AUDIT-C) } \\
\hline Pre-COVID- $19^{\mathrm{d}}$ & 101 & Reference & & & \\
\hline Emerging $^{\mathrm{e}}$ & 57 & $1.13(0.50,2.60)$ & 0.76 & $0.81(0.35,1.89)$ & 0.63 \\
\hline Plateau $^{\mathrm{f}}$ & 80 & $0.76(0.40,1.44)$ & 0.40 & $0.72(0.38,1.38)$ & 0.32 \\
\hline
\end{tabular}

a 20 patients had missing values

${ }^{\mathrm{b}} 5$ patients had missing values

c5 patients had missing value

${ }^{\mathrm{d}} 19$ patients had missing value

e 19 patients had missing value

${ }^{\mathrm{f}} 4$ patients had missing value

$* \mathrm{p}<.05, * * * \mathrm{p}<.005$

had, which was consistent with public health messaging during this time. We observed relatively few individuals in our sample endorsing high rates of depressive symptoms or substance use, although we acknowledge that this was an engaged sample of patients and those who are experiencing more psychosocial challenges may not be represented in this data set. Practice implications involve continuing to screen those who do present for care and reaching out to patients who may have fallen out of care during COVID-19, as they may be those at highest risk for behavioral health and sexual health consequences of the pandemic.

Author contributions All authors contributed to the conception of the paper idea. BGR wrote the initial draft of the manuscript. SCD and JT contributed to the writing. JT conducted analyses. All authors reviewed the final manuscript.

Funding PAC is supported by funding from the National Institute of Mental Health (R01MH114657). JT is funded by K01MH119960. 
Author time for BGR also came from Providence/Boston Center for AIDS Research Grant P30AI042853. MM and BGR are supported by Gilead Sciences (IN-US-276-5463).

\section{Declarations}

Conflict of interest MM and BGR receive funding from Gilead Sciences Grant \#IN-US-276-5463. There are no other relevant financial or non-financial interests to disclose.

Ethical approval Approval was granted for review of de-identified clinical data by the Institutional Review Board at The Miriam Hospital.

Consent to participate A waiver of consent was granted for review of de-identified clinical data for research purposes.

Consent for publication A waiver of consent was granted for review of de-identified clinical data for research purposes.

\section{References}

1. COVID-19 Map [Internet]. Johns Hopkins Coronavirus Resource Center. https://coronavirus.jhu.edu/map.html. Accessed 25 Nov 2020

2. Jakovljevic M, Bjedov S, Jaksic N, Jakovljevic I. COVID-19 pandemia and public and global mental health from the perspective of global health securit. Psychiatr Danub. 2020;32(1):6-14.

3. Pfefferbaum B, North CS. Mental health and the COVID-19 pandemic. N Engl J Med. 2020;383(6):510-2.

4. Torales J, O'Higgins M, Castaldelli-Maia JM, Ventriglio A. The outbreak of COVID-19 coronavirus and its impact on global mental health. Int J Soc Psychiatry. 2020;66(4):317-20.

5. Blumenthal D, Fowler EJ, Abrams M, Collins SR. Covid19-implications for the health care system. N Engl J Med. 2020;383(15):1483-8.

6. Horn DM, Haas JS. Covid-19 and the mandate to redefine preventive care. N Engl J Med. 2020;383(16):1505-7.

7. Jiang H, Zhou Y, Tang W. Maintaining HIV care during the COVID-19 pandemic. Lancet HIV. 2020;7(5):e308-9.

8. Shiau S, Krause KD, Valera P, Swaminathan S, Halkitis PN. The burden of COVID-19 in people living with HIV: a syndemic perspective. AIDS Behav. 2020;24(8):2244-9.

9. Meyerowitz EA, Kim AY, Ard KL, Basgoz N, Chu JT, Hurtado RM, et al. Disproportionate burden of coronavirus disease 2019 among racial minorities and those in congregate settings among a large cohort of people with HIV. AIDS Lond Engl. 2020;34(12):1781-7.

10. Pampati S, Emrick K, Siegler AJ, Jones J. Changes in sexual behavior, PrEP adherence, and access to sexual health services due to the COVID-19 pandemic among a cohort of PrEP-using MSM in the South. MedRxiv Prepr Serv Health Sci. 2020;47(7):431.

11. Viswanathan S, Detels R, Mehta SH, Macatangay BJC, Kirk GD, Jacobson LP. Level of adherence and HIV RNA suppression in the current era of highly active antiretroviral therapy (HAART). AIDS Behav. 2015;19(4):601-11.

12. HIV and Gay and Bisexual Men [Internet]. Center for Disease Control and Prevention. https://www.cdc.gov/hiv/group/msm/ index.html

13. Mustanski B, Garofalo R, Herrick A, Donenberg G. Psychosocial health problems increase risk for HIV among urban young men who have sex with men: preliminary evidence of a syndemic in need of attention. Ann Behav Med. 2007;34(1):37-45.

14. Parsons JT, Grov C, Golub SA. Sexual compulsivity, co-occurring psychosocial health problems, and HIV risk among gay and bisexual men: further evidence of a syndemic. Am J Public Health. 2012;102(1):156-62.

15. Parsons JT, Millar BM, Moody RL, Starks TJ, Rendina HJ, Grov C. Syndemic conditions and HIV transmission risk behavior among HIV-negative gay and bisexual men in a U.S. national sample. Health Psychol. 2017;36(7):695-703.

16. Tulloch TG, Rotondi NK, Ing S, Myers T, Calzavara LM, Loutfy MR, et al. Retrospective reports of developmental stressors, syndemics, and their association with sexual risk outcomes among gay men. Arch Sex Behav. 2015;44(7):1879-89.

17. Friedman MR, Stall R, Silvestre AJ, Wei C, Shoptaw S, Herrick A, et al. Effects of syndemics on HIV viral load and medication adherence in the multicentre AIDS cohort study. AIDS. 2015;29(9):1087-96.

18. Glynn TR, Safren SA, Carrico AW, Mendez NA, Duthely LM, Dale SK, et al. High levels of syndemics and their association with adherence, viral non-suppression, and biobehavioral transmission risk in Miami, a U.S. City with an HIV/AIDS epidemic. AIDS Behav. 2019;23(11):2956-65.

19. Harkness A, Bainter SA, O'Cleirigh C, Mendez NA, Mayer $\mathrm{KH}$, Safren SA. Longitudinal effects of syndemics on ART non-adherence among sexual minority men. AIDS Behav. 2018;22(8):2564-74.

20. Blashill AJ, Brady JP, Rooney BM, Rodriguez-Diaz CE, Horvath KJ, Blumenthal J, et al. Syndemics and the PrEP cascade: results from a sample of young latino men who have sex with men. Arch Sex Behav. 2020;49(1):125-35.

21. Kroenke K, Spitzer RL, Williams JBW. The patient health questionnaire-2: validity of a two-item depression screener. Med Care. 2003;41(11):1284-92.

22. Bush K. The AUDIT alcohol consumption questions (AUDIT-C) an effective brief screening test for problem drinking. Arch Intern Med. 1998;158(16):1789.

23. Shilo G, Mor Z. COVID-19 and the changes in the sexual behavior of men who have sex with men: results of an online survey. J Sex Med. 2020;17(10):1827-34.

24. Sanchez TH, Zlotorzynska M, Rai M, Baral SD. Characterizing the impact of COVID-19 on men who have sex with men across the United States in April, 2020. AIDS Behav. 2020;24(7):2024-32.

25. Santos G-M, Ackerman B, Rao A, Wallach S, Ayala G, Lamontage E, et al. Economic, mental health, HIV prevention and HIV treatment impacts of COVID-19 and the COVID-19 response on a global sample of cisgender gay men and other men who have sex with men. AIDS Behav. 2020;25(2):311-21.

26. Stephenson R, Chavanduka TMD, Rosso MT, Sullivan SP, Pitter RA, Hunter AS, et al. Sex in the time of COVID-19: results of an online survey of gay, bisexual and other men who have sex with men's experience of sex and HIV prevention during the US COVID-19 epidemic. AIDS Behav. 2020. https://doi.org/10.1177/ 1557988320957545.

27. Coronavirus Disease 2019 (COVID-19) How to protect yourself $\&$ others [Internet]. Centers for Disease Control and Prevention; 2020. https://www.cdc.gov/coronavirus/2019-ncov/prevent-getti ng-sick/prevention.html

28. Kahler CW, Wray TB, Pantalone DW, Kruis RD, Mastroleo NR, Monti PM, et al. Daily associations between alcohol use and unprotected anal sex among heavy drinking HIV-positive men who have sex with men. AIDS Behav. 2015;19(3):422-30.

29. Weinhardt LS, Carey MP. Does alcohol lead to sexual risk behavior? Findings from event-level research. Annu Rev Sex Res. 2000;11:125-57. 
30. Rogers BG, Mendez NA, Mimiaga MJ, Sherman SG, Closson EF, Tangmunkongvorakul A, et al. "I wasn't in my right mind": qualitative findings on the impact of alcohol on condom use in patients living with HIV/AIDS in Brazil, Thailand, and Zambia (HPTN 063). Int J Behav Med. 2019;26(1):17-27.

31. Starks TJ, Jones SS, Sauermilch D, Benedict M, Adebayo T, Cain D, et al. Evaluating the impact of COVID-19: a cohort comparison study of drug use and risky sexual behavior among sexual minority men in the U.S.A. Drug Alcohol Depend. 2020;216:108260.

32. Barlow DH, Allen LB, Choate ML. Toward a unified treatment for emotional disorders. Behav Ther. 2004;35(2):205-30.

33. Ettman CK, Abdalla SM, Cohen GH, Sampson L, Vivier PM, Galea S. Prevalence of depression symptoms in US adults before and during the COVID-19 pandemic. JAMA Netw Open. 2020;3(9):e2019686.

34. Xiong J, Lipsitz O, Nasri F, Lui LMW, Gill H, Phan L, et al. Impact of COVID-19 pandemic on mental health in the general population: a systematic review. J Affect Disord. 2020;277:55-64.
35. DiMatteo MR, Lepper HS, Croghan TW. Depression is a risk factor for noncompliance with medical treatment: meta-analysis of the effects of anxiety and depression on patient adherence. Arch Intern Med. 2000;160(14):2101.

36. Berg CJ, Michelson SE, Safren SA. Behavioral aspects of HIV care: adherence, depression, substance use, and HIV-transmission behaviors. Infect Dis Clin North Am. 2007;21(1):181-200.

Publisher's Note Springer Nature remains neutral with regard to jurisdictional claims in published maps and institutional affiliations. 